\title{
ANÁLISE DA IMPORTÂNCIA NO CRESCIMENTO ECONÔMICO DAS COOPERATIVAS DE CRÉDITO NO BRASIL A PARTIR DE 2010
}

\author{
ANALYSIS OF THE IMPORTANCE FOR THE ECONOMIC GROWTH OF CREDIT \\ COOPERATIVES IN BRAZIL FROM 2010
}

\author{
Kalinka Martins da Silva \\ Instituto Federal de Goiás, GO, Brasil \\ E-mail:kalinkamartins@yahoo.com.br \\ José Luis Oreiro \\ Universidade Federal de Brasília, DF, Brasil \\ E-mail: joreirocosta@yahoo.com.br
}

Recebido em: 18.12.2019 - Aceito em: 18.01.2020

DOI: http://dx.doi.org/10.5902/2526629241625

RESUMO: O objetivo deste artigo é analisar a importância das cooperativas no sistema de crédito no Brasil e sua relevância no crescimento econômico. As cooperativas de crédito têm por objetivo prestar assistência creditícia e de serviços bancários aos seus associados. Neste artigo se considera que as cooperativas de crédito estão inseridas no setor financeiro bancário no Brasil. Constata-seque estas estão aumentando sua participação no Sistema Financeiro Nacional devido às medidas desregulatórias promovidas pelo Banco Central (BACEN), a partir dos anos 2000 , e com isso aumentando sua participação no sistema de crédito bancário brasileiro.

Palavras-Chave: Crescimento econômico; Crédito; Cooperativas de Crédito.

ABSTRACT: The aim of this paper is to analyze the importance of cooperatives in the credit system in Brazil and the importance of this in economic growth. Credit unions aim to provide credit and banking assistance to their members. In this article it is considered that credit unions are inserted in the banking financial sector in Brazil, and it is found that they are increasing their participation in the National Financial System due to the deregulatory measures promoted by BACEN from the 2000s and thereby increasing their participation. In the bank credit system in Brazil.

KeyWords: Economic growth; Credit; Credit Cooperatives. 


\section{INTRODUÇÃO}

As cooperativas são instituições financeiras bancárias porque, têm a capacidade de "criar" moeda por meio da multiplicação de depósito à vista, apesar de algumas especificidades, assumindo a função de banco comercial.

Com a promulgação da Lei $n^{\circ} 4.595 / 1964$ as cooperativas de crédito passaram a ser equiparadas às instituições financeiras bancárias, constando no Sistema Financeiro Nacional e sendo supervisionadas e fiscalizadas pelo Banco Central do Brasil. Essa lei permitiu o desenvolvimento do segmento cooperativista, culminando com a criação de dois bancos cooperativos na década de 1990 .

O objetivo deste artigo é fazer uma revisão da literatura sobre o sistema bancário e sua importância no crescimento econômico, destacando o papel das cooperativas de crédito no contexto do sistema bancário, e analisar os dados das cooperativas de crédito no Brasil: o seu tamanho, a sua evolução e sua consolidação.

Este artigo apresenta-se dividido em quatro seções. Além da presente introdução, a seção dois analisa o papel dos mercados financeiros e do mercado de crédito na intermediação de recursos entre os agentes poupadores e investidores. A seção três apresenta os dados da participação do sistema de cooperativas de crédito no Brasil, com objetivo de analisar o tamanho do setor e as suas possibilidades de expansão. Por último, a quarta seção apresenta uma síntese das principais conclusões deste artigo.

\section{O MERCADO DE CRÉDITO E SUA IMPORTÂNCIA NO CRESCIMENTO ECONÔMICO}

Os mercados financeiros são o lócus no qual ocorrem as relações, ou transações financeiras. Essas transações consistem na transferência do comando de recursos monetários por parte de um agente econômico para outros agentes, tendo como contrapartida o reconhecimento de uma obrigação (e de seu serviço) por parte do beneficiário.

O mercado financeiro é divido em instituições bancárias e instituições não-bancárias. As instituições que podem "criar" moeda estão inseridas no chamado sistema monetário, que são o Banco Central (que cria a moeda manual) e os bancos comerciais (que criam moeda escritural).

Para Carvalho et al. (2007), os bancos comerciais são as instituições autorizadas pelo Banco Central a receber depósitos à vista, sendo assim as únicas 
instituições capazes de criar um substituto perfeito para o meio circulante. Nesse contexto, os bancos comerciais se comportam mais como criadores de crédito do que intermediadores de poupança.

No mercado de crédito, as transações são feitas de forma individualizada, identificando-se as partes que realizam o empréstimo. Dessa transação resultam obrigações que são, em princípio, intransferíveis ou inegociáveis, pois os contratos são desenhados de modo a satisfazer as demandas específicas dos tomadores e dos emprestadores, em termos de taxa de juros, prazos, garantias, etc. 0 mercado de crédito se divide em: 1) Crédito de curto-prazo: fornecido, primordialmente, pelos bancos comerciais; e 2) Crédito de longo-prazo: no caso brasileiro, é fornecido quase que unicamente pelo Banco Nacional de Desenvolvimento Econômico e Social (BNDES).

Nos estágios iniciais de desenvolvimento do capitalismo, o volume de recursos necessários para a abertura e a expansão de uma empresa era pequeno. Nesse contexto, a expansão dos negócios podia ser feita de forma fundamentalmente orgânica, financiada com base nos lucros retidos.

As novas tecnologias desenvolvidas a partir da segunda metade do século XIX aumentaram o volume de capital necessário para a realização do processo produtivo. Dessa forma, se fazia necessário aglomerar capitais dispersos entre um número muito grande de indivíduos para que fosse possível o financiamento e a implementação dos projetos de investimento.

Para o financiamento desses projetos, as instituições financeiras possuem um papel importante, porque os poupadores e os investidores não são as mesmas pessoas. Dessa forma, as instituições financeiras têm como objetivos: aproximar os agentes poupadores e investidores, oferecer informações a ambas as partes da transação e criar liquidez para o sistema econômico.

Agindo como intermediadoras de crédito, as instituições financeiras aumentam ou limitam a mobilização de poupança e do investimento, favorecendo ou desfavorecendo o processo de crescimento econômico, pois é devido a sua existência que o investimento precede a poupança.

As instituições financeiras desempenham, ao menos, duas importantes funções numa economia capitalista:

- Aglomeração de capitais - captação de poupança dos investidores e;

- Transferência de recursos das unidades superavitárias para as unidades deficitárias.

- No entanto, o sistema bancário desempenha ainda duas outras funções 
importantes: a função seletiva e a função de monitoramento.

- Função seletiva: selecionar entre as alternativas disponíveis de utilização dos recursos, aqueles que são as melhores;

- Função de monitoramento: monitorar o comportamento dos tomadores para garantir que os recursos transferidos serão devolvidos aos seus proprietários originais, acrescidos do retorno prometido pelo uso dos recursos.

Nesse sentido, além da intermediação financeira, o sistema bancário "escoIhe" os investidores e também faz o monitoramento da capacidade de pagamento desses agentes. No caso brasileiro, as relações predominantes são as de crédito, ou seja, o sistema financeiro brasileiro é um sistema em que predominam as relações financeiras intermediadas - um banco interpõe as suas próprias obrigações no processo de canalização de recursos do emprestador para o tomador.

Nessa modalidade, o risco de crédito recai sobre a instituição bancária que faz o empréstimo, não sobre as relações financeiras desintermediadas: o emprestador - último - retém consigo diretamente as obrigações do tomador final.

Um dos primeiros grandes autores que defendeu a importância do sistema financeiro no desenvolvimento econômico foi Schumpeter (1982). O autor destaca o papel importante da moeda:

De onde vêm o dinheiro, não vêm da parcimônia. Esse método de obter dinheiro é da criação de poder de compra pelos bancos, não pressupõe a existência de resultados acumulados no período anterior. A criação de um novo poder de comprar a partir do nada. O banqueiro é essencialmente um fenômeno do desenvolvimento (Schumpeter, 1982).

Por outro lado, a ortodoxia econômica considera a moeda como neutra e com isso não existe impacto no lado real da economia. A economia é vista como unidades econômicas individuais que busca a satisfação de suas necessidades, essa satisfação é feita pela maximização da divisão do trabalho e da troca dos excedentes. A relação dos bens trocados (oferta e demanda) determina os preços relativos, nesse tipo de economia a moeda é neutra porque representa apenas o facilitador das trocas.

Lucas (1988), um representante fiel desse pensamento, descarta a possibilidade de que as finanças sejam uma variável importante para o desenvolvimento econômico, ou seja, a moeda não afeta as decisões econômicas.

Neste artigo iremos nos apoiar no referencial teórico pós-keynesiano, segundo o qual, a moeda não só é não neutra, como ainda entra no sistema eco- 
nômico por meio do crédito fornecido pelas instituições bancárias; sendo apenas controlada parcialmente pelo BACEN. Dessa forma, as instituições bancárias não são neutras sobre o lado real da economia.

O traço mais distinto da teoria econômica de Keynes é o papel da moeda na concepção dinâmica de economias modernas de produção. Uma economia monetária é aquela em que a moeda afeta motivações e comportamento dos agentes econômicos, tanto no curto como no longo prazo; a moeda não é vista como um mero facilitador das trocas. (Carvalho, 2008).

$\mathrm{Na}$ concepção de Keynes (1936), a moeda assume três funções: unidade de conta, meio de pagamento e reserva de valor. Deve-se ressaltar, contudo, que outros ativos também são capazes de desempenhar a função de reserva de valor. Para que a moeda possa efetivamente concorrer com os demais ativos na composição do portfólio dos agentes econômicos; é necessário que a moeda possua algum atributo que the permita compensar o fato de que, na comparação com os demais ativos, ela é a que possui o menor rendimento explicito (no caso da moeda, o rendimento explícito é igual à zero). Esse atributo é a liquidez.

Como a moeda é o instrumento no qual todas as obrigações contratuais são especificadas e liquidadas, então ela é o poder de compra na forma geral, tornando-se assim o seguro universal contra eventos adversos, principalmente no caso em que os tomadores de decisão possuem dívidas que os obrigam a fazer uma série de pagamentos contratuais, no presente e no futuro. "[...] funciona como um "tranquilizante" contra as limitações, uma vez que as previsões das decisões são feitas no presente, procurando estabelecer um possível resultado futuro. Ou seja, a existência de incerteza cria uma demanda por ativos líquidos; sendo, portanto, o fundamento da preferência pela liquidez (Oreiro, Paula e Sobreira, 2019).

Como a moeda é criada? Para responder essa pergunta é necessário ter em mente que todas as vertentes pós-keynesianas rejeitam explicitamente a chamada visão "verticalista" -, de que bancos centrais podem determinar perfeitamente a oferta de moeda, a qual seria completamente inelástica às variações da taxa de juros. A discussão pós-keynesiana, por sua vez, está dividida grosso modo entre horizontalistas e estruturalistas, dizendo respeito ao grau e as causas da endogeneidade da oferta de moeda.

Segundo a visão horizontalista, desenvolvida por Kaldor (1982) e Moore (1988), a curva de oferta de moeda é horizontal no espaço quantidade de moeda/ juros, porque os ofertantes de moeda sempre acomodam plenamente a demanda por moeda a uma dada taxa de juros. Em uma economia de moeda-crédito, a cria- 
ção de moeda resulta das necessidades de financiamento de gastos - das firmas, das famílias e do governo - e pelas decisões de portfólio dos bancos.

Neste sentido, oferta e demanda por moeda são interdependentes. O Banco Central (BACEN), como emprestador de última instância (garantidor da liquidez das instituições financeiras), define apenas a taxa de juros básica e fornece fundos aos bancos a essa taxa em quantidade ilimitada, tendo, portanto, um papel acomodatício. Os bancos, por sua vez, provêm os empréstimos que são demandados a custos, aproximadamente, constantes (dado o mark-up determinado pelo seu grau de monopólio) e nunca são constrangidos em termos de suas reservas, dada a possibilidade de acessar a qualquer momento as linhas de financiamento do BACEN'.

Já a visão estruturalista engloba um conjunto diversificado de economistas pós-keynesianos, que se contrapõem a visão horizontalista ao sustentarem uma "endogeneidade parcial da oferta de moeda", uma vez que não só as autoridades monetárias deixam de fornecer necessariamente os fundos para os bancos de forma ilimitada - e por isso a taxa de juros tende a subir, quando a demanda por moeda cresce mais rapidamente que a oferta de reservas do BACEN (o que torna a oferta de moeda positivamente inclinada, mas não horizontal). Os bancos não necessariamente atendem a totalidade da demanda por empréstimos dos agentes não-financeiros, devido às mudanças nas suas expectativas quanto ao futuro que impactam na sua maior ou menor preferência pela liquidez e ainda na capacidade do BACEN restringir a oferta de reservas ${ }^{2}$.

Na versão estruturalista da teoria pós-keynesiana da moeda e do crédito, os bancos detêm a posição chave, na transição de um menor nível de atividade para um maior, pois se eles se recusarem a atender a maior demanda de crédito; então haverá uma elevação da taxa de juros (ver figura 1), o que poderá desestimular o investimento, impedindo dessa forma a elevação do nível de atividade econômica.

Para Oreiro, Paula e Sobreira (2019), os bancos comerciais - como qualquer agente que opera sob incerteza não-probabilística - têm preferência pela liquidez que podem levá-los a racionar a oferta de crédito, ao mesmo tempo que sua capacidade de inovação permite a eles expandir a oferta de crédito no "boom" cíclico em relação às exigências de reservas e aos parâmetros regulatórios do Banco Central

\footnotetext{
1 Isso não quer dizer, no entanto, que essa visão seja incompatível com o fenômeno do racionamento de crédito. Conforme enfatizado porHein (2008, p. 44), os bancos determinam a taxa de juros dos empréstimos bancários com base num mark-up sobre a taxa de juros de curto-prazo fixada pelo banco central ofertando todo o crédito que é demandado a essa taxa por aqueles tomadores que são avaliados como "merecedores de crédito". Os bancos são, portanto, formadores de preço e tomadores de quantidade, dentro dos limites dados pela avaliação da credibilidade dos tomadores de crédito.

2 Uma visão representativa desta abordagem é Dow (2006). Cabe ressaltar que houve uma ampla discussão na revista Journal of Post Keynesian Economics entre horizontalistas e estruturalistas. Uma apresentação extremamente didática dessa controvérsia pode ser obtida em Hein (2008, p. 43-53).
} 
A preferência pela liquidez dos bancos é condicionada pela sua percepção de incerteza, criando assim uma demanda de proteção contra os imprevistos no futuro, e que tenham o potencial de afetar de forma adversa a sua situação econômico-financeira. Um aumento da preferência pela liquidez dos bancos irá deslocar a curva de oferta de crédito para cima, aumentando assim a taxa de juros dos empréstimos bancários; o que irá reduzir o nível de gastos dos agentes econômicos e, por conseguinte, o nível de produção e de emprego (Oreiro, Paula e Sobreira, 2019).

Em conjunto com os bancos comerciais, as cooperativas de crédito - que segundo Carvalho et al. (2007) são instituições não voltadas para o lucro, mas funcionam de modo semelhante aos bancos comerciais - complementam a estrutura de crédito e favorecem o crescimento econômico.

O setor cooperativista é de singular importância para a sociedade, na medida em que promove a aplicação de recursos privados e assume os correspondentes riscos - em favor da própria comunidade, onde se desenvolve, - especialmente nos aspectos de formação de poupança e de financiamento de iniciativas empresariais que trazem benefícios evidentes em termos de geração de renda (Soares, 2008).

\section{DADOS DAS COOPERATIVAS DE CRÉDITO NO BRASIL A PARTIR DOS ANOS 2010}

O objetivo desta seção é trazer dados que corroboram o aumento da participação das cooperativas de crédito no SFN. O SNCC (Sistema Nacional de Cooperativa de Crédito) está estruturado em sistemas compostos por cooperativas singulares, cooperativas centrais, confederações de cooperativas e bancos cooperativos.

As cooperativas singulares ( $1^{\circ} \mathrm{grau}$ ) são aquelas constituídas pelo número mínimo de 20 pessoas físicas, necessárias para compor a administração da sociedade. As cooperativas centrais ou federações de cooperativas $\left(2^{\circ} \mathrm{grau}\right)$, são compostas de, no mínimo, três cooperativas singulares de crédito. E as confederações de cooperativas ( $3^{\circ} \mathrm{grau}$ ), são formadas, pelo menos, por três federações de cooperativas de crédito ou cooperativas centrais de crédito.

Segundo o BACEN (2017), em dezembro de 2017, existiam quatro sistemas de três níveis formados por confederação e/ou banco cooperativo, centrais e singulares filiadas: Cresol e Unicred, cujas confederações são autorizadas pelo BACEN como instituições financeiras; e Sicoob e Sicredi, cujas confederações não prestam serviços financeiros, que são fornecidos pelos respectivos bancos cooperativos. Além dos sistemas de três níveis, havia seis sistemas de dois níveis 
formados por centrais e filiadas; e duzentas singulares independentes, não vinculadas a nenhum tipo de sistema (Tabela 1 ).

Tabela 1 - Distribuição das cooperativas em níveis - Dez 2017

\begin{tabular}{c|c|c|c|c|c|c}
\hline $3^{\circ} \mathrm{Grau}$ & Sicredi & Sicoob & Unicred & Cresol & $\begin{array}{c}\text { Não vinculadas a } \\
\text { nenhum sistema }\end{array}$ & $\begin{array}{c}\text { Não vinculadas a } \\
\text { nenhum sistema }\end{array}$ \\
\hline $2^{\circ} \mathrm{Grau}$ & 5 & 16 & 4 & 4 & 6 & \\
\hline $1^{\circ} \mathrm{Grau}$ & 116 & 464 & 34 & 110 & 43 & 200 \\
\hline
\end{tabular}

Fonte: BACEN (2017)

No ano de 2018 o SNCC observou um processo de consolidação, com redução de $4 \%$ na quantidade de cooperativa de $1^{\circ}$ grau, como demonstra a Tabela 2.

Tabela 2 - Distribuição das cooperativas em níveis - Dez 2018

\begin{tabular}{c|c|c|c|c|c|c}
\hline $3^{\circ} \mathrm{Grau}$ & Sicredi & Sicoob & Unicred & Cresol & $\begin{array}{c}\text { Não vinculadas a } \\
\text { nenhum sistema }\end{array}$ & $\begin{array}{c}\text { Não vinculadas a } \\
\text { nenhum sistema }\end{array}$ \\
\hline $2^{\circ} \mathrm{Grau}$ & 5 & 16 & 4 & 4 & 5 & \\
\hline $1^{\circ} \mathrm{Grau}$ & 114 & 449 & 35 & 91 & 44 & 192 \\
\hline
\end{tabular}

Fonte: BACEN (2018)

As incorporações foram o principal motivo dessa redução, totalizando 36 eventos. Além disso, ocorreram 4 dissoluções de sociedade e 2 liquidações extrajudiciais, e nenhuma cooperativa de crédito foi aberta no ano de 2018 (BACEN, 2018).

Esses dados comprovam que existe uma consolidação no SNCC, resultante das normas e regulamentação do BACEN, somado ao crescimento econômico baixo no período, as cooperativas respondem com enxugamento e diminuição dos custos a esse cenário. Em 2015 e 2016, a atividade econômica recuou 3,5\% e $3,3 \%$ respectivamente. E em 2017 e 2018 o crescimento foi de 1,1\% para os dois anos (BACEN, 2018). 


\section{Gráfico 1 - Evolução do número de cooperativa de crédito de $1^{\circ}$ grau}

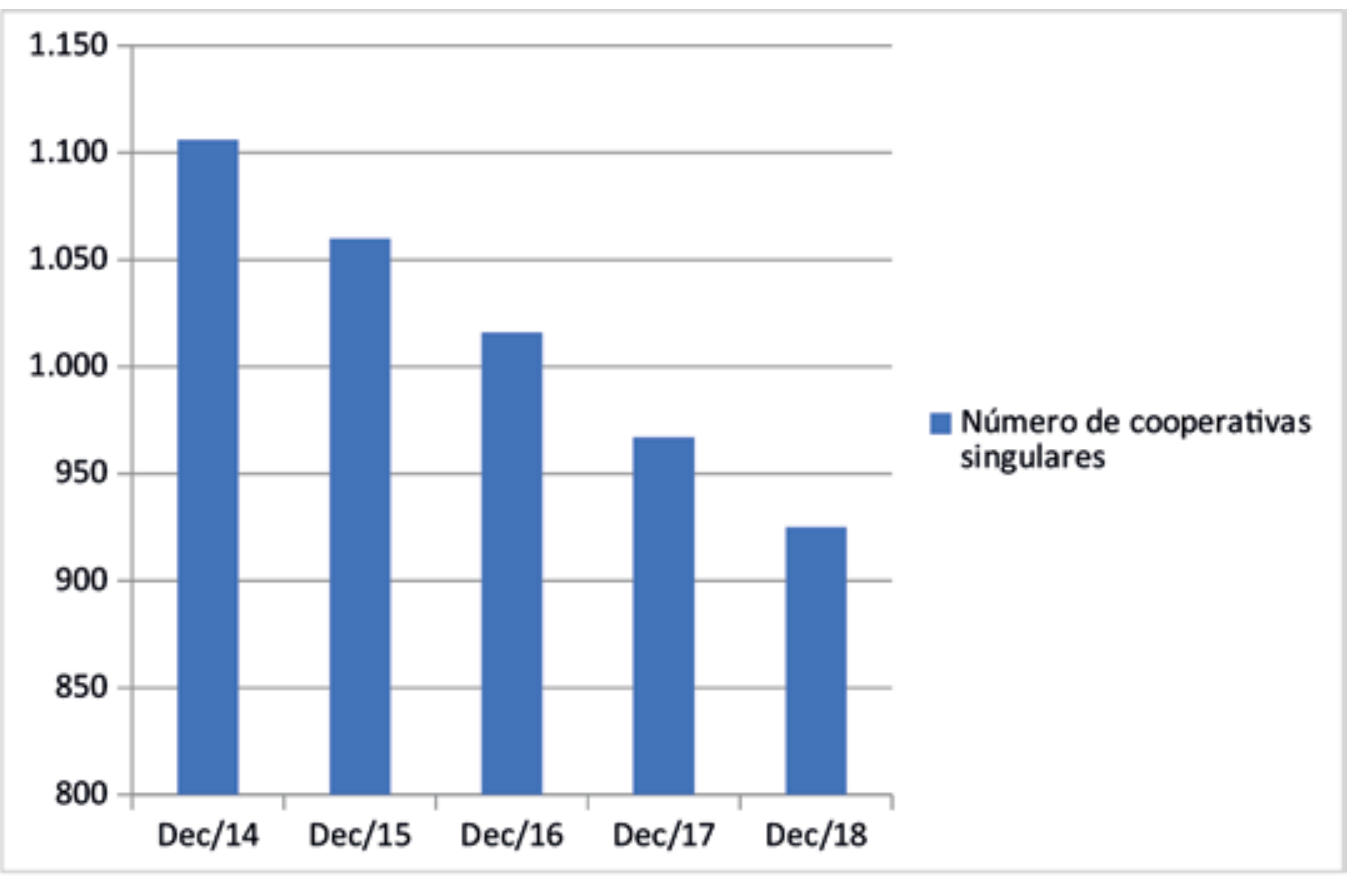

Fonte: BACEN, 2018.

Quanto ao patrimônio líquido, a representatividade dentro das instituições bancárias, segundo dados do BACEN (2018), em 2002 representava 1,30\%, passando para $5,77 \%$ em 2017 ; os ativos eram de $1 \%$ e aumentaram para $2,2 \%$ e os depósitos passaram de 1,5\% para 3,96\%. Dados que demonstram um crescimento e uma possibilidade de crescimento, no sentido que o SNCC ainda não está consolidado no Brasil.

Quanto ao total de ativos e depósitos, houve um aumento na participação dentro do SFN, como demonstram a TABELA 3.

Tabela 3 - Ativos Totais e Depósitos Totais (em bilhões de reais)

\begin{tabular}{c|c|c|c|c|c}
\hline Variável & 2013 & 2014 & 2015 & 2016 & 2017 \\
\hline Ativo Total & 92,2 & 110,6 & 130,5 & 154,2 & 178,5 \\
\hline \% nos Ativos Totais do SFN & $\mathbf{1 , 4 1 \%}$ & $\mathbf{1 , 4 9} \%$ & $\mathbf{1 , 5 8} \%$ & $\mathbf{1 , 8 7 \%}$ & $\mathbf{2 , 1 5 \%}$ \\
\hline Depósito Total & 50,6 & 74,2 & 74,2 & 91,0 & 105,6 \\
\hline \% nos Depósitos do SFN & $\mathbf{2 , 6 9 \%}$ & $\mathbf{3 , 5 5} \%$ & $\mathbf{3 , 5 5 \%}$ & $\mathbf{4 , 2 6 \%}$ & $\mathbf{4 , 5 0 \%}$ \\
\hline
\end{tabular}
Fonte: BACEN (2017)

A participação das cooperativas de crédito no SFN, ainda é pequena, mas à medida que o sistema consolide, com incorporações, ganhos de economia de escala, desregulamentação do setor, aumento da exposição ao risco e uma maior 
cobertura nacional, a participação no SFN será maior.

Um exemplo da capacidade de expansão é mostrado pelo Índice da Basiléia que é uma medida internacional de requerimento de capital instituído pelo Comitê da Basiléia, promovido pelo BIS (Bank for International Settlements), que aconselha os sistemas bancários a terem uma razão mínima entre capital próprio e capital de terceiros. O índice varia de $0 \%$ a $100 \%$, sendo que quanto mais próximo de $0 \%$ maior a alavancagem, que é calculada dividindo o PR (patrimônio de referência) pelo valor dos ativos ponderados de risco."

O BACEN exige que esse índice esteja em 11\% para os bancos brasileiros. No ano de 2016, o índice do sistema bancário brasileiro era em média de $18 \%$ e das cooperativas de crédito estava em 30\% (BACEN, 2016). Assim, as cooperativas de crédito trabalham com índice de alavancagem muito baixo existindo espaço para aumento de crédito sem aumentar a exposição aos riscos.

Outra fonte de expansão seria uma maior cobertura de municípios no país, a tabela 4 demonstra a desigualdade da distribuição geográfica no Brasil. Apesar de aumentar a cobertura de municípios atendidos por região entre os anos de 2013 e 2017, a desigualdade entre regiões é grande. As regiões Sul, Centro-Oeste e Sudeste apresentam maior percentual de municípios cobertos em detrimento às regiões Nordeste e Norte.

Tabela 4- Cooperativismo de Crédito no Brasil: municípios atendidos por região

\begin{tabular}{c|c|c|c|c|c|c|c}
\hline Região & 2011 & 2012 & 2013 & 2014 & 2015 & 2016 & 2017 \\
\hline Centro-oeste & $39 \%$ & $24 \%$ & $47 \%$ & $49 \%$ & $50 \%$ & $52 \%$ & $53 \%$ \\
\hline Nordeste & $7 \%$ & $8 \%$ & $8 \%$ & $8 \%$ & $9 \%$ & $9 \%$ & $10 \%$ \\
\hline Norte & $13 \%$ & $14 \%$ & $15 \%$ & $17 \%$ & $19 \%$ & $22 \%$ & $23 \%$ \\
\hline Sudeste & $49 \%$ & $50 \%$ & $51 \%$ & $53 \%$ & $54 \%$ & $54 \%$ & $56 \%$ \\
\hline Sul & $84 \%$ & $86 \%$ & $88 \%$ & $90 \%$ & $90 \%$ & $91 \%$ & $91 \%$ \\
\hline Total & $39 \%$ & $40 \%$ & $42 \%$ & $43 \%$ & $44 \%$ & $45 \%$ & $46 \%$
\end{tabular}

Fonte: BACEN (vários anos).

As regiões Norte e Nordeste possuem menos de 30\% atendidos por cooperativas de crédito, cenário que demonstra um mercado grande a ser explorado pelo segmento e que a possibilidade de expansão é grande, necessitando, assim, de um incentivo do Banco Central do Brasil para aumentar a participação. 


\section{CONSIDERAÇÕES FINAIS}

O segmento de cooperativas de crédito no Brasil, embora ainda em processo de expansão, vem se destacando como instituição financeira bancária. Esta expansão pode ser observada como resultado dos processos de mudança e de estruturação que vem sofrendo desde a implantação da Lei n4595/1964, que as equiparou as demais instituições financeiras bancárias.

Os principais avanços nas diretrizes de funcionamento ocorreram em1995 com a permissão da criação dos bancos cooperativos e em 2000, ano em que é permitido aos bancos atuarem como bancos múltiplos e com a permissão de investidores fora do sistema cooperativo, até no percentual de $49 \%$ de ações com direito a voto.

No ano de 2003 mais desregulamentação com a permissão de criação de cooperativas de livre admissão em municípios de até 200 mil habitantes, número que foi modificado em 2007 para 2 milhões de habitantes. E, por fim, no ano de 2010 foi permitida a atuação em municípios com número de habitantes superior a 2 milhões, contanto que essas cooperativas possuíssem capital mínimo de 25 milhões de reais, auditoria externa, entre outras exigências.

As cooperativas ajudam a melhorar o crescimento econômico, pois colaboram na aglutinação de capital e oferecem serviços de prestação bancária semeIhantes aos bancos comerciais, além de terem especificidades que beneficiam os associados, pois possuem caráter social, que visa à pessoa e não o capital.

Conforme os dados demonstrados no trabalho, a participação é pequena no SFN, mas após o ano de 2010 aconteceu um crescimento na participação de depósitos e de ativos dentro do SFN, e existe a possibilidade de uma expansão, como demonstrado pela exposição do risco e pela cobertura nacional ainda baixa.

\section{REFERÊNCIAS}

Brasil. (1964). Lei . $^{\circ} 4.595$, de 31 de dezembro de 1964. Dispõe sobre a política e as instituições monetárias, bancárias e creditícia, cria o Conselho Monetário Nacional e dá outras providências. Presidência da República - Subchefia para Assuntos Jurídicos. Recuperado de: http://www. planalto.gov.br.

BACEN, Banco Central do Brasil. (2017). Panorama do sistema nacional de crédito cooperativo. Brasil. Recuperado de: http://www.bcb.gov.br.

BACEN, Banco Central do Brasil. (2018). Panorama do sistema nacional de crédito cooperativo. Brasil. Recuperado de: http://www.bcb.gov.br. 
Carvalho, F. C. (2008). Estrutura e Padrões de competição no Sistema Bancário Brasileiro: uma Hipótese para Investigação e Alguma Evidência Preliminar. In: Paula, L. F., \& Oreiro, J. L. (org.). Sistema Financeiro: uma análise do setor bancário brasileiro (p. 103-123). Rio de Janeiro: Elsevier.

Carvalho, F. J. C. et al. (2007). Economia Monetária e Financeira: Teoria e Política. ( $2^{\mathrm{a}}$ ed.). Rio de Janeiro: Elsevier.

Cooperativismo de crédito. Recuperado de: www.cooperativismodecredito. com. br.

Carvalho, F. C.(1992) Mr Keynes And The Post Keynesians: Principles of Macroeconomics for a Monetary Production Economy.Edward Elgar: Aldershot.

Dow, S. (2006). Plurality in economics, SCEME Working Papers: Advances in Economic Methodology 011/2006, SCEME.

Hein, E. (2008). Money, Distribution conflict and Capital Accumulation. Palgrave Macmillan: Londres.

Lucas, R.E. (1988). On the mechanics of economic development. Journal of Monetary Economics 22.

Kaldor, N. (1982). The Scourge of Monetarism. Oxford University Press: Nova Iorque.

Keynes, J.M. (1973). The General Theory of Employment, Interest and Money. MacMillan: Londres [edição original: 1936].

Moore, B. (1988). Horizontalists and Verticalists: the macroeconomics of Credit Money. Cambridge University Press: Cambridge.

Oreiro, J. L., Paula, L.F., \& Sobreira, R. (2019). Preferência pela Liquidez, Acumulação de Capital e Elasticidade da Oferta de Crédito: as contribuições de Fernando Carvalho para o Programa de Pesquisa Pós-Keynesiano. In: Oreiro, J. L., Paula, L.F, \& Sobreira, R. (orgs.). (2019). Moeda e Sistema Financeiro: ensaios em homenagem a Fernando Cardim de Carvalho. Editora da UFSM: Santa Maria.

Organização das cooperativas brasileiras. Recuperado de: www.ocb.com.br.

Schumpeter, A. J (1982). Teoria do desenvolvimento econômico: uma investigação sobre e lucros, capital crédito, juro e o ciclo econômico. São Paulo: Abril (Os Economistas).

Soares, M. M. (2018). Microfinanças: o papel do Banco Central do Brasil e a importância do cooperativismo de crédito. (2 ed). Brasília: Banco Central do Brasil. Recuperado de: http://www.bcb.gov.br. 